Heiko Schulz*

\title{
Changing one's mind: Reconsidering Fisch's idea of framework transitions in (partly) Kierkegaardian fashion
}

https://doi.org/10.1515/opphil-2020-0144

received October 6, 2020; accepted October 27, 2020

\begin{abstract}
The article critically engages Menachem Fisch's account of normative frameworks, in particular of (rational) transitions between them. I argue, first, that exposure to the normative criticism leveled at us by other human beings is indeed "capable of destabilizing normative commitment" to one's own underlying framework beliefs and standards, as Fisch holds; however, closer scrutiny reveals that such exposure is neither sufficient nor necessary but rather accidental in this respect. Second, I will try to show that Søren Kierkegaard's account of how people fundamentally change their mind provides resources for both a substantial critique of Fisch and a more adequate understanding of the transitions in question. The article argues, third, that Fisch's framework model - though meaningful, in fact heuristically indispensable in and as of itself - has robust transcendental implications which as such are being ignored, if not directly denied by Fisch and, precisely by being ignored or denied, unnecessarily weaken the overall plausibility of his account. Finally, and ex post, I will address an important objection raised by some commentators.
\end{abstract}

Keywords: Kierkegaard, framework transition, subjectivity, self, event, principle of charity, understanding, pre-rationality, transperspectivism

\section{Introduction}

Let me start with an example from Martin Buber's famous collection of Chuang-tse-parables:

Chuang-tse and Hui-tse were standing on the bridge leading over the river Hao. Chuang-tse said: Look, all those minnows whizzing around! That's the joy of the fish. 'You are no fish,' said Hui-tse, how can you know what the joy of fish consists in? 'You are not I,' replied Chuang-tse, 'how can you know that I do not know what the joy of fish consists in?'1

As far as fish qua members of a nonhuman species are concerned, there may be, according to the brief parable just quoted, some controversy regarding the nature, facticity and possible sources of their joy or enjoyment. Not so in the case of one very specific Fisch - the one who goes by the name of Menachem. At least when it comes to philosophizing, we not only know for sure that, but also why he takes great pleasure - pleasure, namely, in the Talmudic literature: this, as he notes, "conducts its [...] reflection by means of well-crafted narratives rather than by abstract philosophical reasoning." When one undertakes to

1 Buber, Tschuang-Tse, 87 (my trans.).

2 Fisch, "Deciding by Argument," 123.

\footnotetext{
* Corresponding author: Heiko Schulz, Department of Protestant Theology, Goethe-University Frankfurt, Frankfurt am Main, Germany, e-mail: heiko.schulz@em.uni-frankfurt.de
}

Ә Open Access. ( 2020 Heiko Schulz, published by De Gruyter. (cc)BY This work is licensed under the Creative Commons Attribution 4.0 International License. 
honor Fisch for his accomplishments, both as a philosopher and in particular as an avid reader and profound interpreter of the Talmud, it makes sense to take his own narrative preferences into account, and so the decision to start with a parable should come as no surprise.

However, there is yet another, in fact supplementary reason why I chose to follow this path and, in particular, why I intend to draw on the parable just quoted in a more substantial way: in my opinion it takes us straight into the epicenter of problems that Fisch's account of how people "change their minds" raises. Here I must ask for the reader's patience, though: I will return to the issue at the end of my article. I intend, first, to give a brief account of Fisch's views concerning cognitive framework transitions in Section 2. Second, in Section 3, I will sketch the (largely anthropological) presuppositions of an alternative approach, inspired, among others, by Søren Kierkegaard's (1813-1855) notion of subjectivity, in order, subsequently, to utilize these resources for a critique of Fisch's pertinent views in general, in Section 4; his missing attention to the transcendental dimension of framework transitions, in particular, in Section 5. In Section 6, a sixth paragraph, added ex post, I will address an important objection raised against my account by some readers. In Section 7, a brief conclusion will round things off in a more personal manner.

\section{Fisch's key idea}

Following in the footsteps of Menachem Fisch, the conference, on which the original version of the present article was based, set out to explore how people "change their mind" in a very fundamental way, moreover, whether such changes can be deemed rational at all and, if so, under what conditions. The issue is a pressing one, not only from a theoretical or cognitive but also from a practical, in particular moral and religious or interreligious perspective. Humans not only hold a variety of beliefs but also presuppose and assess these beliefs' rationality or irrationality, according to certain formative standards and norms. These frequently tacit "frameworks" of belief, judgment and conduct are not easily made explicit, though, much less abandoned by their respective subjects, even if they come under closer scrutiny and critique, especially from the outside. And yet, outside critique, that is critique leveled at them from our fellow human beings is, according to Fisch, the only possible - or at least: a "sufficient[]" one's mind," at least in a rational manner, especially when it comes to cognitive framework transitions. For here the only conceivable alternative would be a critical "view from within" - and the latter is unavailable or, more precisely, outright "impossible." ${ }^{5}$ Nobody, or so at least the argument goes, can adopt a rational and as such sufficiently "critical stance toward her own normative framework;" for how, one might ask, as Fisch himself does, "can a person's norms and standards be effectively subjected to her own rational appraisal, if it is by means of those very standards that she rationally appraises?"

Following Harry Frankfurt and Charles Taylor, Fisch then argues that it is others (and others only) who gradually make us change our minds - and do so in a rational manner. What they do and can do for us, in particular, when it comes to reconsidering the "[s]trong evaluations" 8 within the fabric of our underlying normative framework, is to "ambivalate" 9 the latter by calling them into question and thereby to help us suspend our wholehearted commitment to them.

Now in what follows, I will counter Fisch's approach by presenting some Kierkegaard-inspired arguments against its major thesis - yet thereby in some sense perhaps also complying with it, since the approach both explicitly and implicitly invites and encourages doubt and contradiction. Surely, "exposure

3 Fisch, "The Normative Challenge," 4.

4 Cf. in context Fisch and Benbaji, The View from Within.

5 Fisch, "The Normative Challenge," 4; cf. also Fisch, "The Talmudist Enlightenment," 4ff.

6 Fisch, "The Normative Challenge," 3.

7 Ibid., 4 (my emphasis).

8 Fisch, "Lost for Words," 5.

9 Cf. ibid., passim. 
to the normative criticism leveled at us by others" (sc. other human beings) is indeed "capable of destabilizing normative commitment;" 10 and yet, closer scrutiny reveals, at least in my opinion, that this outer criticism is neither sufficient nor necessary but rather remains accidental in this respect. Moreover, I will argue that Kierkegaard's account of how people fundamentally change their minds offers resources for a more plausible alternative to Fisch's approach, an alternative that will eventually lead us to realize that under certain conditions even normative self-criticism will do. ${ }^{11}$ Finally, I will challenge Fisch's account in yet another respect: If I am not mistaken, the framework model - though meaningful, in fact heuristically indispensable in and as of itself - has robust transcendental implications, which as such are overlooked, if not directly denied by Fisch and thus unnecessarily weaken the overall plausibility of his account.

\section{Kierkegaard's doctrine of self and subjectivity}

1. Let me begin by invoking a rather notorious claim from Søren Kierkegaard's late journals, according to which God is the only one who "relates objectively to his own subjectivity."12 For the time being, I feel entitled to ignore what this somewhat enigmatic statement might mean with regard to God himself; for my primary, in fact exclusive, concern pertains to the issue of human subjectivity.

Now it is obvious from the entry's context that, contrary to God, human existence is, according to Kierkegaard, characterized by a deep and ineradicable tension, a unique ambivalence of first- and secondorder subjectivities; for being human means, at least among other things, being compelled to relate subjectively to one's own subjectivity. The Sickness unto Death from 1849, one of Kierkegaard's major anthropological works, published under the pseudonym Anti-Climacus, expresses something similar by way of saying that being human essentially means being a self, such that the latter in turn amounts to being "a relation which relates itself to itself."13 Peter is a self (more exactly: he is his having to be a self), precisely by constantly struggling to establish and preserve a balance or equilibrium between certain first- and secondorder concerns. Accordingly, it does not suffice simply to conceive of him as a - first-order - synthesis of body and soul or of finitude and infinity (see below), when it comes to specifying what makes him human; rather, a specific second-order dimension, pertaining to the (volitionally potentialized) self-reflection of the former synthesis, has to be taken into account and supplemented for an adequate picture to emerge.

2. As an example to illustrate what is meant here one might consider the first-order phenomenon of wishing: in some way, a person wishing for something transcends her finite situation (she "infinitizes," so to speak $^{14}$ ) by means of imagination, in that the latter helps to create a picture of an object as apparently worthwhile of possession. This object being imagined as desirable is as such connected with a certain quality of feeling, of will and of cognition. Striking on the one hand is that even in those cases in which imagination is not explicitly self-reflexive in nature (in our context: where there is no consciously imagined conception of oneself as the object of desire) but is intentionally directed toward any given attractive object (for instance, some toy as the content of a child's wish) - that even in those cases the subject of imagination at least tacitly or subliminally mirrors herself, on a second-order level, so to speak, in the imaginatively

10 Ibid., 5; cf. also Fisch, "Ambivalence as a Value," 1ff.

11 In what follows, the reader should not expect a full-fledged presentation of Kierkegaard's (in particular, pseudonymous) views on the matter at hand. As is well-known, both Either/Or (1843, in particular volume two) and Philosophical Fragments (1844) would be highly pertinent to such a presentation. Since my approach is largely critical and not so much constructive, much less purely hermeneutical, I will draw on the Kierkegaardian resources only to the extent that I consider them relevant to my overall project.

12 Kierkegaard, Journals and Papers, 364.

13 Kierkegaard, Sickness, 13.

14 Cf. ibid., $35 f$. 
anticipated state of fulfillment of the wish in question. In other words, the ultimate object of any wish is the subject of wishing itself. ${ }^{15}$

This takes us straight back to the Kierkegaardian idea of human existence as an instance of subjectively relating (and having to relate) to its own subjectivity. In wishing for something, for instance a luxury car, Peter ultimately relates to (an idea/l of) himself - a self favorably to be mirrored in the imaginatively anticipated fulfillment of his wish. And yet, this imaginative "self of fulfillment" is anticipated - nota bene: on a second-order level or qua "spirit" - precisely by virtue and in the medium of his first-order wish for the desired item. This observation prompts and justifies a distinction between three basic layers or dimensions of a self:

(a) In desiring or wishing for something Peter synthesizes, on a first-order level, body and soul.

(b) In doing so, he is at least tacitly aware, on a second-order level ("spirit"), of himself as a self - a self to be realized by the envisaged fulfillment of his wish.

(c) This awareness, however, is and can only be instantiated in the very medium of his first-order synthesis and thus remains dependent upon and psychologically affected by it. ${ }^{16}$

3. To be sure, in being a self, Peter is determined consciously to relate to himself $a$ s a self (that is, on a second-order level, by means of reflection and volition); yet he does and can do so only within and by means of his self as an immediate relation of body and soul (that is, on a first-order level). His reflection and volition are therefore deeply affected, perhaps even distorted by an immediate body and soul synthesis, which is expressed in every act of wishing and which includes those basic desires, emotions and ideas that form an integral part of the latter. Accordingly, he finds himself compelled subjectively to relate to his own subjectivity: he can only reflectively address and volitionally cope with the realizability and legitimacy of his own wish in the very medium of the wish - nota bene: the very same wish, which in turn bears upon the genesis, shape and direction of its second-order counterpart.

And yet there is a third and final element to be taken into account at this point, in order to fully understand and appreciate the structural complexity of the self. For our first-order informed second-order reflections and volitions pertain to, bear upon, express and reflect our deepest commitments to what in our opinion makes existence meaningful as a whole; yet they can do so only by virtue of a serious (at least implicit) metaphysical commitment - a commitment to something unconditional or quasi-divine, which as such is supposed to bestow ultimate meaning to our complex mode of existing as human beings. We do not simply wish for some $\mathrm{X}$ or Y; we do so, rather, in the attempt to live in accordance with what we perceive as "ourselves" in light of an (often tacit) metaphysical notion of living or being - a notion in which the fulfillment of that wish is supposed to play a vital role.

Accordingly, Anti-Climacus maintains that, in subjectively relating to oneself, the self simultaneously relates to some "absolute other," perceived as having established the whole "self-system" in its first- and second-order complexity. ${ }^{17}$ The argument he provides is "negativistic" (to borrow a term from M. Theunissen ${ }^{18}$ ) and as such derived from "aberrational" (in Kierkegaardian terms), that is, desperate forms of existence. As pointed out earlier, the true and ultimate object of any wish is the subject of wishing itself. Thus conceived, however, the phenomenon of wishing is a valid indicator of despair: for if wishing essentially means wishing for oneself; and if the self wished for is different from the wishing self, then it follows that the latter does not want to be itself but another. Yet precisely this evasion or refusal to be

15 In this sense, Anti-Climacus seems justified in identifying the self with imagination, and imagination again with reflection considered as self-reflection; see Kierkegaard, Sickness, 31: "The self is reflection, and the imagination is reflection, is the rendition of the self as the self's possibility."

16 That this latter claim indeed does justice to the text is corroborated by an (unduly neglected) formulation at the beginning of the book; cf. ibid., 13 (my emphasis): "In the relation between two, the relation is the third as a negative unity, and the two relate in the relation to the relation [...] If, however, the relation [sc. qua negative unity] relates itself to itself, this relation is the positive third, and this is the self."

17 Cf. ibid., $13 f$.

18 Cf. Theunissen, "Kierkegaard's Negativistic Method.” 
oneself or, correspondingly, the defiant insistence of wanting to be another, at least implicitly reflects a relation to something or someone as the ultimate ground or telos of selfhood - a ground which the self, albeit reluctantly, perceives as something to which it must accommodate itself in some way or other. Hence, despair functions as a hidden or at least indirect indicator of the irreducible metaphysical dimension of the self-system as a whole, namely, by pointing to God - or so at least the Christian author of Sickness unto Death argues. ${ }^{19}$

\section{Some critical observations in (partly) Kierkegaardian spirit}

Now readers might ask if and to what extent Kierkegaard's doctrine of self and subjectivity, as it was spelled out in the preceding paragraph, actually bears upon a critique of (and alternative to) Fisch's theory of framework transitions. The question is justified, yet I hope to be able to answer it in what follows. For even though Fisch's account of the nature and function/s of cognitive frameworks plus his explanation and epistemic justification of transitions between them is, at least in my opinion, a rich resource, in fact an invaluable tool for better understanding and also critically adjudicating the rationality of Talmudic (and other) discourse/s, his view raises a number of issues; these can and will be addressed here in greater detail, i.a., with recourse to the previous analysis. Accordingly, I will repeatedly draw on what I take to be genuinely Kierkegaardian resources - partly by utilizing (my account of) the doctrine of the self in Sickness unto Death, partly by invoking other Kierkegaardian texts and ideas. Three questions will be raised in particular, the first two of which pertain to the descriptive or genetical, the third to the normative or epistemical implications of the problem at hand: (1) Does Fisch's approach adequately account for the concept and possibility plus (2) the genesis (or, more exactly, the conditions for instantiating) framework transitions? (3) Does he succeed in justifying their rationality?

1. It seems to me that Fisch all too quickly abandons the conceptual issue in favor of the epistemical. As I pointed out earlier, his analysis draws heavily on Harry Frankfurt's theory of first- and second-order volitions - to which he adds some supplementary insights and correctives from Charles Taylor's pen.20

1.1. Following Frankfurt, Fisch argues that the authority with which our fundamental framework beliefs, standards and norms "speak for us, and their power to mobilize us to act on their behalf reside [...] not merely in what we earnestly want, but in what we earnestly want to want."21 In other words, what renders some first-order desire "definitive of who we are, is not the mere power of its pull, but that we deem it [sc. on a second order-level] to be a desired" 22 or, more precisely, a desirable desire. And yet, in turn the "stamp of approval issued by our second-order desires or volitions owes to their wholeheartedness," 23 another key term borrowed from Frankfurt. Thus conceived, our deepest - that is: framework-constitutive commitments are a matter of the will, or more precisely: free will.

Now according to Frankfurt (and Fisch concurs unhesitatingly), "willing freely" boils down to "wanting wholeheartedly what one wants to want;" 24 thus, such willing is not so much "the freedom to do anything, but the freedom to do anything we want to do." ${ }^{25}$ Freedom, in other words, is to be defined by the ability to do what one wants to do, in the sense of being able to want what one does. And yet, ironically enough, this volitional freedom or wholeheartedness itself, in other words: the power, on a second-order level unambiguously and passionately to "want what we want," is not at our disposal; we cannot establish

19 Cf. Kierkegaard, Sickness, $13 \mathrm{f}$.

20 Cf. Fisch, "Lost for Words,” 4f.; cf. Fisch, “Ambivalence as a Jewish Value,” 1ff.

21 Fisch, "Lost for Words," 2.

22 Ibid.

23 Ibid.

24 Ibid. (my emphasis).

25 Ibid. (my emphasis). 
and we cannot "change our will at will,"26 as Fisch aptly puts it in good Schopenhauerian (and for that matter: Lutheran) fashion, from which follows that, "left to our own devices, we can never willfully change our minds." 27

Now what does this somewhat sobering result precisely amount to: that we cannot change our minds at all? That we can only change them by virtue of some external power or force? Or that any such change must be deemed irrational? Fisch argues that in any case it would be rash to jump to the irrationality conclusion based on the diagnosis of the dilemma of internalism just described:

Although we can never convince ourselves or be convinced by others of the unworthiness of norms we're committed to, exposure to the normative criticism of others can on occasion ambivalate us toward the norms they're questioning. And norms to which we become ambivalent lose their wholehearted status, and can be critically [viz. rationally] assessed in the light of our remaining convictions. ${ }^{28}$

The quotation suggests that Fisch wants to have it both ways: That others must and can "ambivalate" us toward the norms they call into question not only helps to explain how we actually begin to waver in commitment to them; it also accounts for the rationality of the latter. Yet in my opinion more is required to drive home (not only, but especially) this latter point: for even if $A$ accounts for $B$, the latter does not explain the possibility of A itself. In other words, before assessing the rationality of framework transitions, we must account for their genesis and/or possibility in the first place.

1.2. Now as far as this latter aspect is concerned, it will come as no surprise in light of my previous remark that Fisch's approach leaves something to be desired here, too - from my perspective, at any rate. To begin with, Fisch's spokesman Harry Frankfurt, although being an avid Kierkegaard-reader himself, fails adequately to account for the possibility of what he rightly calls and appreciates as wholeheartedness. Surely, Frankfurt rightly maintains that, left to our own devices, we must be considered unable to "want what we want" wholeheartedly. Yet how is wholeheartedness possible in the first place? In realizing that the latter is by no means a matter of freedom (more precisely: a matter of free will, for willing freely is itself a mere expression of the former), Frankfurt should have been bold enough to consider it a pure, possibly incomprehensible and as such puzzling event - an event, which as such contingently establishes a fragile balance between first- and second-order selfhood. ${ }^{29}$

Why should anyone accept this claim? Well, not least of all because there is plenty of testimony for its reasonableness - Kierkegaard included: on the one hand he inculcates - in full, if implicit, agreement with the likes of Fisch and Frankfurt - that "purity of heart" (i.e., wholeheartedness) is a matter of willing freely or of wanting (on a second-order level) "what one wants" (qua primary volition)..$^{30}$ Moreover, in the context of his discourse it turns out that the possibility of wholeheartedness - (a) qua willing freely - depends upon the fulfillment of two further preconditions: One must be able (b) to want precisely one thing and (c) not just anything but the good. ${ }^{31}$ For the time being, I must and can ignore these further provisos, since what only matters in the present context is the mutual (if tacit) agreement between Kierkegaard, Fisch and Frankfurt - an agreement according to which wholeheartedness, qua unconditional commitment to one's own framework beliefs, is a matter of freely willing, in other words, of being able to do what one wants, by virtue of being able to want what one does.

26 Ibid., 3.

27 Ibid.

28 Ibid., 4.

29 For a brief, yet illuminating account of the notion "event” and its philosophical significance cf. Zizek, Event, ch. 1.

30 The issue of wholeheartedness - and its opposite: double-mindedness - is extensively dealt with in an upbuilding discourse from 1847, titled “An Occasional Discourse" ("Purity of Heart is to Will One Thing”), cf. Kierkegaard, Upbuilding Discourses in Various Spirits, 7-154. As to the latter's interpretation cf. the pertinent (and often excellent) essays in Lippitt and Stokes, Narrative, Identity and the Kierkegaardian Self, plus Davenport, Narrative Identity, esp. ch. 4.

31 Cf. “An Occasional Discourse,” 33-77. 
1.3. The impression of mutual agreement quickly vanishes, however, if and as soon as we realize that according to Kierkegaard both Fisch and Frankfurt appear to underestimate the difficulties of grasping how wholeheartedness is even possible in the first place. More exactly, they underestimate the (in particular: internal) complications, which arise from and go along with the fact that the self is both structurally and phenomenologically compelled to establish and sustain its second-order volitions in the often conflicting medium of its own first-order volitions, as has been pointed out above. This, precisely, is (at least one of) the lesson(s) to be learned from Sickness unto Death - nota bene: if and as long as the reader is willing to accept my interpretation of the book as roughly correct.

At any rate, it seems consistent in light of these and similar observations to hold, as Kierkegaard does, that, in order to be genetically possible and actual, wholeheartedness, though essentially a matter of free will, ultimately depends on a contingent, yet divinely constituted, balance between first- and second-order volition/s, such that the self, in relating to itself, simultaneously "rests transparently in the power that established it," ${ }^{32}$ from which follows, among other things: no adequate account of (the possibility of) wholeheartedness - even on a mere genetical level - without the inclusion of a genuinely metaphysical perspective, which as such cannot rest content with a merely human but has to invoke the notion of a divine "other." Unfortunately, any such deliberation is missing in Fisch's account. To avoid misunderstandings, I am not claiming here that endorsing such a metaphysical (or more exactly: theological) perspective is, for sheer explanatory purposes, indispensable or necessary. All I want to suggest is that it is at least sufficient for explaining what otherwise must remain a complete riddle in my opinion: the event of wholeheartedness.

2. My second concern pertains to the genetical issue in a stricter sense. It appears to me that the critique, ex hypothesi being leveled at us from the outside, is neither sufficient nor necessary, when it comes to explaining how the shaking of our normative foundations or commitments is possible. It is not sufficient in light of the double fact that there is an obvious semantic difference between doubt and reflection and that, furthermore, our peers can make us reflect at best. Doubt implies reflection but not vice versa. Accordingly, we might very well reflect challenges and objections leveled at us by our peers, without in the least "taking them seriously," so as to begin to doubt them. And even if we begin to doubt, occasioned by some external critique, the question remains, in fact it becomes even more pressing, how any such doubt should possibly come about in the first place, given the fact that ex hypothesi we have to generate the latter on the basis of the very same normative commitments, which are being called into question by it. ${ }^{33}$ Thus, even if what others might do for us prior to and in preparation of a transition in consciousness were necessary, it would hardly be sufficient.

2.1. However, and worse still, such external - nota bene: human - critique cannot even be considered necessary; for there appear to be unambiguous cases of (in particular moral and religious) framework transitions, which simply do not require them. Conversion is a case in point. Here the fundamental normative commitments of the convert - on a cognitive, moral and religious level - are turned upside down and radically reframed; indeed, "the conversion experience restructures basic expectations about the representations of a previously known reality," including "conceptions of time, space, and social relationships." 34 And although, considering the empirical data available, such reframing normally happens in and under the confines of a specific social context, it need not happen in this way; for occasionally conversions come

32 In religious terms, one might want to speak of the (workings of the) Holy Spirit. Cf. also Kierkegaard, Sickness, 14 and 131. 33 A reader of the present article pointed out that doubts don't seem to be things that we "generate" at all but rather "find ourselves having." I agree, doubts are mental events rather than mental acts (except in those special cases in which we doubt methodically and on purpose, hence rather "act as if we doubted"). Yet, this undeniable fact speaks not so much against, but rather in favor of, my argument: For if doubts can neither be generated by the doubting subject alone, in terms of a mere fiat of the will, nor thought of as being brought about or directly induced by others, then the riddle remains how these events are instantiated and/or possible in the first place.

34 Jules-Rosette, African Apostles, 61 and 64. Cf. in greater detail Schulz, “Conversion, Truth and Rationality,” esp. 182ff.; see also Ferreira, Transforming Vision, $105 \mathrm{f}$. 
about without any interference from the social sphere in which the convert lives. What is at stake here appears to be - at least, it can be - a matter between her and God alone. ${ }^{35}$

2.2. Even more striking and theoretically far-reaching is an ethically pertinent type of normative conflict: namely, temptation. Not only does the latter perfectly mesh with Kierkegaard's view of subjectivity, it is also a paradigm case of what Fisch describes as the process of "ambivalating." Now what happens in temptation? First of all, we are dealing with a serious inner conflict, in which specific first- and secondorder volitions are battling against each other, and this is exactly along the lines of Kierkegaard's account; for you can only feel the need to resist temptation, while precisely being in and being drawn to that very state you desperately try not to succumb to at the same time.

Second, one can only feel or experience temptation as such. Hence, it belongs to a class of what I call "propositional” or, more precisely, "categorical terms." By contrast, animals cannot be tempted, because they lack the necessary linguistic and hermeneutical capacities to interpret their own experiences and mental states - or those of their fellow creatures - by utilizing, in particular, categorical means (here, "temptation"). For humans, to be able to perceive the experience they find themselves in as "temptation" is in fact part and parcel of that very experience itself. Third, temptations are self-authenticating; in other words, the subject of temptation cannot go wrong in identifying her own mental state as "being tempted." Most important in the present context is a fourth feature, though: Temptations are self-elusive - and this is despite their self-authenticating character. As with other conflict-laden desires - perhaps also with desires in general! - temptation is marked by a certain dialectic of self-inflicted obscurity and simultaneous, albeit involuntary, self-revelation: we cannot have or generate any of those desires except by denying that we do; and we can just as little deny their presence without tacitly (namely, by way of shame) admitting that we do have them. More precisely, we admit, in the very medium of denying the facticity of temptation, that the object of our desire is to be considered evil and thus to be shunned; yet, at the same time we deny, in the very medium of tacitly admitting that the object of our desire is to be considered evil and thus to be shunned that we actually feel tempted by it.

This considerable inner crisis on the borderline of what Kierkegaard dubs the aesthetical as opposed to the ethical sphere of existence ${ }^{36}$ is a paradigmatic case of clashing normative commitments. If the subject of temptation is capable of resisting the latter, she does so in terms and by virtue of a conscious framework transition. However, she does not make that inner movement, thanks to a destabilizing intervention from outside; for her conflict is of a purely internal kind. Hence, despite their being genuine types of framework transition, neither conversion nor (the overcoming of) temptation requires any critical engagement of a human other: not the former, since here the interlocutor is or at least could be divine; not the latter, since here he might as well be absent altogether.

3. Finally, let's turn to the epistemic issue, in other words, to Fisch's proposal concerning the (possible) rationality of framework transitions. Here I just want to make two closely related points. The first one bears upon the notion of rationality and its implications for "rationally" changing one's mind. It is widely taken for granted, and rightly so in my opinion, that rationality is a virtue. ${ }^{37}$ As such it functions primarily as a

35 Dalton Rambo goes so far as to define conversion as "a total transformation of the person by the power of God" (Rambo, Understanding Religious Conversion, xii) and thus eliminates the - nota bene: mundane or human - intersubjective dimension from the phenomenon in question even conceptually (in my opinion it would be more appropriate to define conversion as "a total transformation of a person by the power of what she takes to be God”). In any case, my major point is that - pace Fisch's contention - the absence of social impact or interference is possible and, at least occasionally, also actual in radical framework transitions. Thus, it is beside the point to invoke - as one reviewer did - counterexamples, for instance, the famous case of Franz Rosenzweig's (almost-)conversion to Christianity under the influence of his friend Eugen Rosenstock-Huessy.

36 As to the term and doctrine of existential spheres (sometimes "stages") cf., for instance, Kierkegaard, Concluding Unscientific Postscript, 501 f.: "There are three existence-spheres: the aesthetic, the ethical, the religious. To these there is a respectively corresponding confinium [border territory]: irony is the confinium between the aesthetic and the ethical; humor is the confinium between the ethical and the religious." For a brief account of Kierkegaard's doctrine in the context of his pseudonymous authorship cf. Amir, "Stages."

37 Cf. Schulz, “Einleitung,” esp. xii-xv; cf. also Schulz, “Theology and Rationality.” 
property of action and conduct - and indirectly also of beliefs, namely, to the extent that the latter can also be considered actions (or at least entail an active element). And yet, rationality is strictly speaking no more than an instrumental or conditional virtue, in that its virtuousness depends on the actual (cognitive, moral and/or religious) value of the purpose that it serves and without which it would lose its proper function and justification. ${ }^{38}$ Hence, the "choice" of those purposes themselves, which as such establish and shape the whole fabric of our deepest normative commitments, is not a matter of rational action or conduct; in fact, it is probably not even a matter of action or choice simpliciter but rather a pre- or transrational event (see above) which prepares for and paves the way to the actuality and/or possibility of the latter. ${ }^{39}$ And since they make rationality possible, our deepest normative commitments can neither be rational nor be irrational themselves, ${ }^{40}$ much less actively be chosen on purpose by a mere fiat of the will. This is the deeper truth in Frankfurt's claim that we cannot want our wanting, will our willing or choose our choosing. ${ }^{41}$ That being said, however, the transition from one normative framework to another can just as little be a matter of rational conduct (plus, on a meta-level, of assessing its rationality) as its inception or first instantiation..$^{42}$

\section{5 (Hidden) transcendental implications of Fisch's view}

As I mentioned at the outset there is, next to the personal, also a more philosophical reason why I chose Buber's parable as a vantage-point for my subsequent reflections: in my opinion the latter points to one of the more serious issues to be raised on account of Fisch's views. Here is Buber's text again:

Chuang-tse and Hui-tse were standing on the bridge leading over the river Hao. Chuang-tse said: 'Look, all those minnows whizzing around! That's the joy of the fish. 'You are no fish,' said Hui-tse, 'how can you know what the joy of fish consists in?' You are not I, 'replied Chuang-tse, how can you know that I do not know what the joy of fish consists in?'43

There are at least three lessons to be learned from Buber's parable. However, in order to prepare for the properly transcendental (=3), I must ask for the reader's patience, plus the permission for a brief

38 Cf. Schulz, "Einleitung,” xviif; cf. also Audi, Rationality and Religious Commitment, ch. 1.

39 As such it touches upon a dimension of the holy or holiness - in other words of something that we unwaveringly cling to and hold most dear, on a deeply emotional level, as an absolutely binding and authoritative realm of values. As to the dialectic between rationality and holiness, see also Schmidt, "Das moralische Gesetz," esp. 643ff.

40 A reviewer read this claim as saying or implying that "normative framework transitions [...] are never rational," thereby insinuating I considered them irrational. But this is misleading, as the formulation above clearly indicates. My basic contention is that radical framework transitions like the ones Fisch describes cannot adequately (that is, phenomenologically and/or epistemically) be couched and accounted for in terms of either rationality or irrationality, since both categories exclusively pertain to means-ends-beliefs and decisions within a given framework.

41 From hence follows that freedom is either impossible or to be considered a gift: a gift, pertaining to the event, experienced as such, of surprisingly being granted a certain amount of "elbow room" (to borrow from Dennett, Elbow Room) for rational choice and conduct but also for perception, interpretation and belief. I am inclined to subscribe to this latter view. Cf. also Ferreira's (Rylean) distinction between "voluntary" and "intentional action" (the latter being performed "on purpose"); she argues that the former appears to be a more appropriate term for explaining transitions to faith or belief, namely, qua (imaginatively informed) "decisions that X is the case" (Transforming Vision, 7) instead of "decisions to do X" (ibid., my emphasis). She then goes on to describe the former (voluntary) decisions of (or for) faith as a mere "letting go of hitherto accepted associations" or, alternatively, as the "surrender of an old vision in the activity of seeing a new way in which things can be together" (ibid., 106), thereby emphasizing, in a quasi-paradoxical or paradoxically dialectic manner, both the active (=decision) and the passive element (=imagination) within such transitions. The term event, however, which in my opinion corresponds to this paradoxical dialectic, in that it calls for momentarily suspending and transcending the language of activity and passivity altogether, is missing in her account.

42 The role of emotions, in particular their genetical as well as epistemical function for the (prereflexive) constitution of normative commitments and their respective (ir-)rationality, must be supplemented and emphasized at this point; cf. Schulz, "Einleitung," esp. xviif.; also and in a wider context de Souza, The Rationality of Emotion.

43 Buber, Tschuang-Tse, 87 (my trans.). 
introductory detour, intended to explain two fundamental hermeneutical implications of Buber's narrative (=1 and 2).

1. The first lesson is that understanding requires and reveals an ontological commitment - a commitment, namely, to subscribe and hold fast to what has aptly been dubbed (or more precisely: adopted as) the "principle of charity" by Donald Davidson. ${ }^{44}$ Perhaps we can never hope fully to understand fish; but if we can - or more precisely: as soon and as long as we pretend and presuppose that we can - we are nolens volens led to imply that those whizzing minnows in Buber's parable are, in some important (epistemical and/or) ontological respect, similar to us - here, in particular: similar in their human-like enjoyment of "whizzing around." ${ }^{45}$ In general, understanding is tantamount to (self-)assimilating, one might say; and whether we are justified in such self-assimilation, we cannot help but assume that a person whom we pretend to understand has (desires and) beliefs very much similar to our own. In fact, we have to presuppose and at least tacitly claim that most of his or her beliefs, precisely by being similar to ours, are true - plus and a fortiori that the other has beliefs in the first place - and this regardless of whether this double assumption actually obtains or not.

Pretty much the same holds for nonhuman beings that we consider to (be able to) understand: If, for instance, we claim to understand a book, we either tacitly or openly perceive it as having been crafted by an intelligent being - in fact, we assert it to be such an entity itself. Puzzling as it might seem, all understanding implies and ends up transforming that which is (to be) understood into something itself capable of understanding. Whatever we claim or pretend to understand is destined thereby to gaze at us, as it were, or so at least we must admit. Ultimately, we do and can only look into mirrors: in the midst of a world resonating with our call to be understood by its own understanding. Hence, for better or worse (especially considering the fact and sheer amount of gratuitous evil in the world, which seems to defy every attempt at "understanding”), there is and can be nothing "absolutely strange in this world" (P. Tillich).

2. There is a second, likewise hermeneutical lesson to be learned from Buber's narrative. For not only does any act of understanding entail a robust ontological commitment to (the principle of) charity; moreover, it is difficult, perhaps impossible, to abstain from claiming to understand. If I am not mistaken, this is precisely the tacit point in Chuang-tse's rhetorical question settling the brief dispute with his friend: Hui-tse can only drive home his argument against Chuang-tse at the expense of pragmatic consistency. If and to the extent that his friend cannot understand the minnows, he himself can just as little understand his friend the very same friend whom he charges for his purportedly unjustified claim to understanding. But this latter assumption must obviously be considered absurd (in particular from Hui-tse's own perspective), and so likewise the former, from which follows that even in those cases in which no clear demarcation line can be drawn between what is comprehensible (in other words, that which at least in principle lends itself to being understood) and what is and perhaps must remain incomprehensible, we can hardly do away once and for all with the apparently unavoidable claim at least in principle to be able to understand or comprehend - including cases of reading other, especially nonhuman minds. And this regardless of the fact that the possibility of understanding is and perhaps must always remain one of the greatest mysteries itself.

Now provided the two lessons spelled out so far are true lessons, the ontological charity just described sanctions, in fact paves the way for, a corresponding epistemic charity according to which the act/s of and understanding of truth ascription are coextensive: As long as you want to preserve the right to claiming your understanding of others, you can do so only by simultaneously being willing to admit that there is and remains a fairly large common ground of belief between you and the other/s, a considerable area of

44 Cf. Davidson, Inquiries, chs. 9 and 13.

45 Understanding in general entails bridging the gap between what is taken for granted as self-evident and what unexpectedly presents itself as running counter to the former and thus calls for being (explained and/or) understood. No understanding without encountering that which as of yet is not understood; and no encountering of the latter without a vast, as of yet unquestioned realm of the self-evident - partly and temporarily being (and experienced as being) suspended by the former. This, in any case, is how I re-read, in somewhat ontological fashion, what Gadamer famously dubbed "Horizontverschmelzung" (merging of horizons; cf. Gadamer, Wahrheit und Methode, 289). 
mutually overlapping beliefs. Conversely, the apparent triumph of dismissing all or nearly all beliefs of others as false or radically misled, comes at a very high price: the other must (at least tacitly) be considered a complete stranger who as such defies any attempt at understanding him.

3. This pertains to the third and final, namely, transcendental, lesson from Buber's tale. I consider it significant in two respects: first, as a reflex and confirmation of Kierkegaard's structural analysis of subjectivity. Having to relate subjectively to one's own subjectivity here means, per analogiam, that one can rightfully claim to understand only in the very medium of (at least partial) truth ascription in relation to what one claims to understand. Now at first sight this might be taken to imply or lead to a strong epistemic perspectivism: Other requirements notwithstanding, the possibility of understanding is ultimately based upon subjective and thus inevitably perspective-dependent acts of truth ascription. Invoking Fisch's vocabulary, one might speak of an irreducible framework dependence of human cognition and understanding. A closer look reveals, however, that the ascription in question is rooted in a trans-perspectivist claim to universality. As such it makes - and must make, for the sake of consistency - an appeal to truth with a capital "T," so to speak.

So what we are left with is the perhaps epistemically disquieting fact that, precisely in order to be able to insist, as Fisch does, upon an irreducible framework dependence of human cognition, we must necessarily, and at least tacitly, appeal to some transcendental, hence framework constitutive, yet independent realm of thought - and this, for the sake of consistency, from within some purported framework. ${ }^{46}$ In other words, we must lay claim to what seems unavailable at the same time. And yet we can only assert and maintain the unavailability of such a transcendental realm by virtue of always already laying claim to and making use of it, thus rendering it unavoidable. This seeming paradox of an intrinsic conjunction or mutual dependence of perspectivism and transperspectivism, ${ }^{47}$ framework dependence and independence, calls for, makes possible and encourages an attitude of what has aptly been dubbed by Menachem Fisch epistemic humility. ${ }^{48}$ And, as I may add, it is perhaps only the former which calls for, makes possible and encourages the latter: a fact, which in my opinion has been ignored or at least unduly - and unnecessarily - been underestimated by Fisch. ${ }^{49}$

\section{Appendix ex post: addressing an objection}

1. Some commentators of the present article in its original form raised a substantial objection against it which I would like to address here as an appendix to my former argument because it seems to jeopardize the latter's overall feasibility and as such merits special attention. According to these readers, it is precisely Kierkegaard's account of the transition between the aesthetical and the ethical stage of existence - and

46 This point has been spelled out in greater detail in Schulz, "Positionalität und Perspektivität."

47 For a particularly subtle account of these and related implications cf. Godlove, Religion, Interpretation, and Diversity of Belief; also and still to be consulted in this context: Lauth, Die absolute Ungeschichtlichkeit der Wahrheit.

48 Cf. Fisch, “A Modest Proposal.”

49 In order to avoid misunderstandings, I would emphasize that I actually find Fisch's idea of epistemic humility very appealing, both epistemically and ethically. What I wish to criticize is that, at least in the former respect, Fisch inadvertently weakens the appeal of his own idea by ignoring or even denying its robust transcendental implications. A reviewer of the present article failed to realize this; he argued that my account actually, though unwittingly, showed how the transcendental implications of the framework model in fact "strengthen (instead of weaken) Fisch's theory, since those implications are said to pertain to and support the idea of epistemic humility" - the very same idea, which, as I myself openly admit, "is a vital matter for Fisch.” The objection is beside the point, however; for it is obviously one thing to formulate and/or hit upon a true or fruitful idea; it is quite another to acknowledge, or even perceive or realize, the full range of its (here, epistemical) implications. 
here, in particular, the pertinent issues raised in the second volume of Either/Or (1843) ${ }^{50}$ - which may be invoked as a counterargument to the approach pursued above: For one thing, the transition in question is a paradigmatical framework shift and is doubtlessly presented in Either/Or as such; for another, the shift obviously refers to a change of mind, which in equally paradigmatic fashion is claimed by Kierkegaard and/ or his pseudonyms to depend on the intervention of a (nota bene: human) other. Both observations seem to dovetail nicely with and in fact support Fisch's view. However, upon closer scrutiny, the objection turns out to be rash and largely unwarranted.

2. In order to see why, let us take a quick glance at Judge William's second letter to his friend, the aesthete A. Here, as is well-known, William's slogan is "either/or:" "either a person has to live aesthetically or he has to live ethically." ${ }^{51}$ For a fuller grasp of the meaning and, in particular, the argumentational function and scope of this maxim, we must look more closely at some of its key tenets and implications.

2.1. First and foremost, it must be noted that the either/or motto is brought to bear by an ethicist. ${ }^{52}$ The fact, in other words, that under certain conditions (cf. 2.3 below) a choice has to be made - a choice, namely, between two ways of life or life views, the aesthetical and the ethical - is itself a genuinely ethical claim, a claim made from the stance and vantage point of someone who takes himself to be among those who (and who rightly) choose to pursue the ethical way of life instead of the aesthetical. Borrowing from Fisch, one might say it is a claim made by someone who (not only, but also) in his or her own opinion has experienced a radical normative framework shift in the direction of the ethical.

2.2. Equally important - yet also more intriguing - is the content issue: Which object has to be chosen, when the choice is ethical? Considering that it must constitute and express a radical framework shift (a transition from one way of life to another), one finds that it evidently cannot be reduced to a mere choice of some individual $X$ supposed to represent an ethical good, value or virtue (say neighbor-love, justice etc.). It is not even sufficient that a person chooses or decides for such a good vis-à-vis evil (or some entity Y as an expression or representation of the latter), such that one might speak of a "choice between good and evil [Valget mellem Godt og Ondt]" ${ }_{33}$ - nota bene: in favor of the former. What is at stake, rather, on the most fundamental level, is a transition to and a choice of certain (here, meta-ethical) standards or principles of (ethically) choosing, hence a transition to a radically new normative framework - a real "cast of mind" (Revolution der Denkungsart) in Kantian terms. Among those principles are the following54: (a) in order to be able to choose on a secondary level (=between good and evil), one must first and most fundamentally make a primary "choice by which one chooses good and evil [Godt og Ondt]" 55 - namely, as absolute, unconditional and incommensurable opposites. (b) The awareness that one must do so - in other words: the awareness that such a "meta-move" is necessary, urgent or "momentous" (W. James) ${ }^{56}$ - is integral to and in fact part and parcel of the very same act of (primary) choice. From which follows, among other things, that there is simply no other way to find out about the meaning and reasonableness of the act than by performing it; this notwithstanding, the fact that it actually calls for being performed must itself be chosen. (c) Both the (ethical) good and its absolute opposition to evil are real only for and in the medium of choosing and of choosing them; hence, the act of (ethically) choosing simultaneously establishes itself (sc.

50 Cf. Either/Or II, esp. Judge William's second letter to his friend (ibid., 155-333) and here, in particular, the former's doctrine of choice (valg): cf. ibid., 157 and passim (esp. 166-9, 177f., 207-19). For a brief, yet concise introduction to Either/Or as a whole cf. Hannay, Kierkegaard, 58-66; as to Judge William's ethics in particular cf. Evans, Kierkegaard's Ethic of Love, 34-60.

51 Either/or II, 168 (my emphasis).

52 Accordingly, William's friend and addressee, the aesthete A, is portrayed "from the outside and from the vantage-point of an ethical life-view" (Hannay, Kierkegaard, 60).

53 Either/Or II, 169 (my emphasis).

54 I continuously, yet loosely, draw on Judge William's formulations in the following; for a closer reading of the crucial passages cf. Schulz, Eschatologische Identität, 255-62.

55 Either/Or II, 169.

56 Cf. James, “Der Wille zum Glauben,” 129ff. 
the category of choice) as its own normative fundament and theoretical framework. ${ }^{57}$ (d) By choosing the idea or category of choice as a metaethical principle, and by simultaneously instantiating the act of choosing that principle as a genuinely ethical act, one also chooses the absolute difference of this latter act from any other (in particular, aesthetical) act of "choice." 58 (e) Finally and in choosing along the lines of (a)-(d), the subject of choice simultaneously constitutes him- or herself as a self; in other words, as an instance or entity which is deemed, by itself, to be both metaphysically and ethically capable of performing the proper primary and secondary choice/s previously described..$^{59}$

2.3. Now my presumption that a full-fledged account of Judge William's concept of choice must do justice to the (in particular: structural) complexity of choosing in a "primary" or metaethical sense (a complexity which is typical for genuine framework-transitions à la Fisch) finds support in the fact that the either/or of William's maxim ("either a person has to live aesthetically or he has to live ethically") is neither strictly logical - namely, qua complete disjunction ${ }^{60}$ - nor unconditional or context independent. It is not logical, since both options (living aesthetically/living ethically) express contraries at best: although, when considered as principles or full-fledged life views, they cannot be true at the same time, both might and in fact do eventually turn out to be wrong (for instance, in terms and from the perspective of a third: the religious, in which both the aesthetical and the ethical life view are sublated, hence preserved, yet only as intrinsic elements, not as principles). Moreover, the Judge himself hastens to add what he considers an important argument for living ethically rather than aesthetically: The former is capable of incorporating, actualizing and preserving the (at least certain) interests of the latter but not vice versa. ${ }^{61}$

On the other hand, William's either/or is not unconditional, either, due to its being context sensitive or situation dependent: Advising or urging someone to choose, in the way explained above, makes sense only if the addressee is (rightly) taken to be in a position which finds him able and willing to listen and to be receptive to the advice given to him. A, the aesthete, appears to fulfill these conditions, yet only to a certain degree and in a rather ambiguous way. Following William's account, one might best describe A's attitude as a half-hearted and ultimately dishonest attempt to perpetuate the aesthetical way of life, in order, namely, to postpone and possibly evade an unambiguous and wholehearted transition to the ethical. Correspondingly, his overall mental state shows signs of inner restlessness, disunion, melancholy or despair. ${ }^{62}$

2.4. Two conditions apply, in particular, when it comes to assessing this situation from an ethical vantage point: first, A apparently tries to stage or direct his life in a "both/and" fashion instead of adopting a consistently either/or stance, yet precisely through his trying (though in vain) to do so his standpoint expresses a neither/nor. Accordingly, William observes that A belongs to all those who do not "live aesthetically, but neither has the ethical become manifest to them in its wholeness." ${ }^{3}$ Yet at the same time A can just as little rid himself of the ethical, once (and since) it has revealed itself to him as a new and disquieting normative option. In B's view A's real predicament lies in the fact that a person who, like him,

57 Accordingly, William speaks of "choosing to will [at vælge det at ville]" (ibid., 169) and I read this to mean at least two things: (a) to choose to will some X (here, the ethical) wholeheartedly; (b) to choose to consider "wholehearted willing" as a principle of properly (i.e., ethically) choosing.

58 Judge William explains that his "Either/Or designates the choice by which one chooses good and evil or rules them out [eller udelukker dem]" (ibid., 169; my emphasis). According to my reading, the latter option is, from William's own perspective, not meant to admit of and point to an equally legitimate alternative, to the effect that it could also, at least in principle, be chosen ethically (or in short, be chosen). Rather, the formulation refers - on a purely descriptive level - to the aesthetical stance, which as such is not defined as evil, but as "indifferent" (ibid.): A knows about good and evil, but other than B refuses to choose them as absolute, unconditional, incommensurable and unreconcilable opposites (cf. Schulz, Eschatologische Identität, 260f, note). 59 As to the implications of choosing oneself cf. Either/Or II, 211-6.

60 An "unqualified dilemma [fuldstændigt Dilemma]" (ibid., 219), as he puts it.

61 Cf. ibid., 271-7. Hence, the either/or does not imply any belief, on the part of Judge William, that a life of duty is incompatible with and thus excludes a life of pleasure. By contrast, it preserves the possibility of the latter, in his opinion, namely, by saving it from its hyperbolic claim to being a principle instead of just a subordinate, yet integral element of (here, ethical) existence. 62 Cf. ibid, 207-13.

63 Ibid., 169 (my emphasis). 
"chooses the aesthetic after the ethical has become manifest to him is not living aesthetically,"64 either, and thus violates the either/or principle. ${ }^{65}$ Second, and as a corollary to the predicament just mentioned, A is characterized as refusing to choose in any stricter (viz. ethical or metaethical) sense. A's choice, as William inculcates, is aesthetic but strictly speaking "an aesthetic choice is no choice" ${ }^{66}$ at all. The aesthete does not choose in any stricter sense, because his "choice" (of aesthetically desirable or pleasing objects, in particular) does not imply, much less express, any honest awareness, on his part, of a pressing either/or. Yet this is tantamount to saying that he does not choose ethically or the ethical, or more precisely, that he does not choose at all: for the ethical "is essentially that which makes the choice a choice" (ibid., 168). What is absent here, in particular, is the primary or metaethical dimension of choice, which corresponds to the awareness and wholehearted acceptance, on the part of its subject, of an urgent or momentous either/or; for, as I pointed out earlier (as I hoped, in the spirit of the Judge), the either/or must first and foremost be chosen as such, and A obviously lacks the willingness and/or capacity, wholeheartedly to face and comply with that task. ${ }^{67}$

3. Now let us finally return to the issue raised at the beginning of this paragraph: ethical choices à la Judge William are presented in Either/Or II as paradigmatic framework shifts. These shifts refer to a change of mind, which in equally paradigmatic fashion is claimed by Kierkegaard to depend upon the intervention of a (nota bene:) human other. Both observations seem to mesh perfectly with Fisch's views stated above and as such raise doubts as to my previous attempt to criticize the latter by utilizing the former. But these doubts are unjustified, hence unnecessary.

3.1. In order to see why, let us first ask about the specifically Kierkegaardian lessons for assessing them: Does he teach us (a) that ethical and/or cognitive framework shifts are impossible (= the conceptual and/or genetical issue); (b) that despite their being possible, they cannot be rational (= the epistemic issue); (c) that both - or none of these - alternatives obtain? What is intended here as a Kierkegaardian contention is, first, that framework transitions are indeed possible, yet only "by virtue of the absurd," as it were; in other words, they are possible, and comprehensible as such, only when one invokes the notion of an ultimately unspecifiable and perhaps paradoxical conjunction of act and event - a conjunction which is typical of emergent phenomena in general. Thus defined, they can, second, neither be rational nor irrational, since their genesis contains a certain prereflective element which as such renders the former trans- or, more precisely, prerational. Both suggestions run counter to Fisch's approach, of course. We saw earlier that in his view normative self-criticism will not do, when it comes to explaining the possibility and genesis of radical framework shifts, and likewise the latter's rationality. Therefore, the transitions in question must either be deemed irrational and/or impossible per se or their rationality and/or possibility depends on something which is out of reach for the subject of transition. Fisch defends the latter view and invokes intersubjectivity as a necessary and sufficient means for explaining how the process of "ambivalating" and gradually undermining deep-seated normative commitments can come about - and be rational, too.

3.2. Now, in my opinion, one lesson to be learned from Either/Or II is that in most practical and/or theoretical matters we ought to apply three rather than just two basic parameters or criteria of judgment: correspondence ("are all or at least some of Peter's beliefs true or false?”/“is Peter's overall conduct morally

64 Ibid., 168 (my emphasis).

65 According to my reading, B takes the aesthetical alternative seriously, indeed. If a consistently aesthetical form of existence were possible - in other words, a way of life in which the subject would either never be or become aware of the ethical as an option at all or at least not as a competing one - it would certainly find Judge William's full and unreserved approval (cf. Schulz, Eschatologische Identität, 256f.).

66 Either/Or II, 166.

67 In Fisch's terms one might say that, genetically speaking, the very first normative framework transition is the transition to (here, ethical) normativity itself. 
good or bad or neither of these?"68); consent or consensus ("do others concur with all or at least some of Peter's practical and/or theoretical beliefs?”); and, finally, consistency (“do Peter's practical and/or theoretical beliefs cohere, such that they form an internally consistent whole in conjunction with all or at least most of his other pertinent beliefs?”). Fisch has taught us how important a (perceived) disagreement or missing consensus with our peers - at least those that we consider authorities in the respective areas - can be, when it comes to possibly, and rationally, abandoning deep-seated framework beliefs or commitments. However, Fisch has unduly neglected the significance of coherence or consistency, and this is precisely, what Judge William brings to the table.

According to the Judge, A's primary - perhaps his one and only-problem is inconsistency: both categorically (the aesthete is living a kind of "threshold existence," which is neither consistently aesthetical nor ethical) and psychologically (A's restlessness, melancholy and despair reflect the categorical problem on a mental and emotional level). Thus, Alastair MacIntyre's infamous critique of B's doctrine, according to which the latter has us think that "the principles which depict the ethical way of life are to be adopted for no reason," ${ }^{69}$ appears to be completely beside the point. Although Judge William does not explicitly present an argument for choosing the ethical, he could do so easily by addressing his friend in the following, entirely rational manner - or at least so it seems:

(1) Whenever a person is and/or believes to be living ${ }^{70}$ on a threshold between the aesthetical and the ethical, her mental state and conduct instantiate both a categorical and a psychological (in short: an "existential") inconsistency.

(2) For someone entangled in or held captive under the burden of an existential inconsistency, choosing is the only option for overcoming the latter.

(3) Choosing ethically or the ethical is the only type of choice, which actually and/or possibly meets the requirements of (2).

(4) You (=A) are entangled in or held captive under the burden of an existential inconsistency.

(5) Therefore, choose the ethical!

3.3. Prima facie this all looks perfectly rational, and I am indeed of the opinion that the syllogism not only dovetails nicely with (at least some of) Judge William's intentions, but that it is also, in and of itself, an argument seriously to reckon with. However, although formally valid, the argument is flawed, due to a hidden ambiguity in its premises; moreover, as will turn out shortly, it is at odds also, in some important respect, with Judge William's views. Ambiguous and thus problematic are premises (2) and (4): even though A might have to be considered, from an external or third person perspective, to be "held captive under the burden of an existential inconsistency," he himself might and in fact does think otherwise, when it comes to assessing his own situation - even if we rightly presuppose that he takes it to be and to express some kind of crisis. ${ }^{71}$ The presumption that a deep-seated, yet as such hidden, discrepancy between first- and thirdperson perspective looms large in the present case is indirectly confirmed by B's advice to A in conjunction with the latter's justification: First and foremost, "[c]hoose despair, because despair itself is a choice

68 Since the focus is on consistency here, my subsequent argument does not rest upon either a correspondence theory of truth or any version of ethical cognitivism and/or realism; hence, I can leave the issue undecided whether, in which way, under which constraints and to what extent it makes sense to hold or imply that our beliefs somehow "correspond" to some subjectindependent (empirical or ideal) reality.

69 MacIntyre, After Virtue, xxxviii (here and hereafter quoted from the reprint of central passages in Davenport, Kierkegaard after MacIntyre, xxxv-xxxix). For an equally comprehensive and astute meta-critique of MacIntyre's argument cf. the pertinent articles in Davenport, Kierkegaard after MacIntyre; in particular, Piety, "Kierkegaard on Rationality" (ibid., 59-74), and Marino, "The Place of Reason in Kierkegaard's Ethics” (ibid., 113-27).

70 I have argued elsewhere, in the context of specifying basic rationality requirements for conversion, that we must tackle the de re- and de dicto-requirements separately, since it is possible that beliefs like the ones mentioned in (1) turn out (namely, in retrospect and from a third-person perspective) to be false, yet the person holding them might nevertheless be or have been fully rational and thus justified in holding them. Cf. Schulz, "Conversion, Truth and Rationality," esp. 189ff.

71 And texts like "Diapsalmata" (Either/Or I, 17-43) or "The Unhappiest One” (ibid., 217-30) suggest that to a certain extent A is indeed aware of his own predicament. 
[Fortvivlelsen selv er et Valg];"72 hence, "in order truly to despair, a person must truly will it." Second, if and whenever "he truly wills it, he is truly beyond despair [saa er man i Sandhed ude over Fortvivlelsen]."73

3.4. Neither of these rather bold claims concerning the nature and the conditions for possibly overcoming despair can be given due hermeneutical credit in the present context; suffice it to say that each of them separately - and a fortiori both combined - lead/s to the conclusion that the denial of despair, on the part of its subject, is inherent in or conditio sine qua non of despair itself. In other words, A cannot despair without desperately wanting to ignore or deny that he is in despair, which brings us back to an earlier point made by Judge William: The ethicist can only choose the ethical; and the aesthete doesn't choose. Accordingly, B declares that the "Either/Or [...] between living aesthetically and living ethically is not an unqualified dilemma [et fuldstændigt Dilemma], because it actually is a matter of only one choice [eet Valg]. Through this choice. I choose the good [det Gode]."74 The ethicist (a) makes a "primary" choice, the choice of facing the momentousness to choose (between the ethical and the aesthetical way of life), thereby simultaneously implying that (b) in order to do so, he can choose the, or something, ethical ("the good") only. By contrast, the aesthete, at least ethically considered, does not, in his exclusive and ultimately arbitrary "selection" of putative pleasures, choose at all, since he remains ultimately indifferent to the primary choice.

Worse still, and here I expand upon and radicalize what has been said above, he cannot even be considered capable of choosing in a stricter, viz. ethical sense; for this would mean to make an impossible move: the move of abandoning the stance, from - and in the very medium of - which he is supposed to make that move. This, precisely, is the Fisch-like mission of transition which the aesthete qua aesthete cannot accomplish, since he is doomed to accomplish it in the very medium which makes that accomplishment both necessary - hence also rational - and impossible at the same time. ${ }^{75}$ The psychological implications of this dilemma are aptly described by the Judge: "the more time that passes by, the more difficult it becomes to choose, for the soul is continuously in one part of the dilemma [Sjælen er bestandig $i$ den ene af Dilemmaets Dele], and hence it becomes more and more difficult to work itself free."76 To which Vigilius Haufniensis, the pseudonymous author of The Concept of Anxiety, can be quoted as a corollary - here with regard to the psychological and ethical conditions of actualizing (human) freedom qua choice between good and evil: "If freedom is given a moment to choose between good and evil, a moment when freedom itself is in neither the one nor the other [uden selv at være $i$ nogen af Delene], then in that very moment freedom is a meaningless reflection." 77

3.5. In light of the foregoing analysis, both the genetical and the epistemical implications of A's dilemma lend themselves to being reformulated in somewhat paradoxical fashion: What ought to be done by A qua aesthete, namely, in order to overcome his despair, he cannot do (=choosing the ethical); if and to the extent that it can be done, any advice or command to that effect is superfluous, for it can be and has in fact always already been done by someone qua ethicist. In short, choosing ethically is possible only if and as long as it is to be considered superfluous; it is necessary as long as it is to be considered impossible. Likewise the epistemic paradox: What would be rational for A to do, in order, namely, to solve his

72 Either/Or II, 211 (my emphasis).

73 Ibid., 213 (my emphasis).

74 Ibid., 219 (my emphasis). "A complete disjunction” would have probably been a more adequate translation than the one preferred by the Hongs ("an unqualified dilemma").

75 I have a certain sympathy with Piety's attempt to defend the rationality of Judge William's plea for choosing the ethical, yet eventually it seems to me to fail; for, given the previous account of A's predicament the ex hypothesi experienced "persistence of suffering" (Piety, "Kierkegaard on Rationality," 61f. my emphasis), on A's part, can neither be considered sufficient for explaining (a) the latter's putative motivation nor (b) the right or reasonableness to abandon the aesthetical in favor of the ethical. In other words, even if A suffers persistently, this persistence need not imply that he himself counts it as a (sufficient) reason to make the transition, much less that he rightly does so, if he does. What is missing here is the (a) inconsistency and (b) the self-denial factor, both of which, taken together, render Piety's apologetical attempt questionable.

76 Ibid., 169 (my emphasis).

77 The Concept of Anxiety, 111f. note (my emphasis). 
inconsistency problem, he, qua aesthete, cannot do - choosing ethically or the ethical. If, on the other hand, he were to be considered capable of choosing, his choice would no longer be rational and/or advisable, since the givenness of that capability would presuppose and imply the very instantiation of choosing ethically, which in turn renders the task of choosing obsolete. Hence, choosing the ethical, and likewise recommending, encouraging or urging such choice, seems rational only, if the latter is to be considered impossible; conversely, it seems possible only to the extent that its recommendation must be considered superfluous - and in that sense irrational.

3.6. But doesn't this leave us with a highly undesirable dilemma? If the aesthete, qua aesthete, cannot and a fortiori: cannot rationally - make the transition; and if the ethicist, qua ethicist, need not - and by the same token, cannot rationally be asked to - make it, how can (here, ethically) normative framework transitions, as such and as possibly rational, be accounted for in the first place? Or do we rather have to assume, given the paradox just spelled out, that there simply is no possible - much less: rational - transition from the aesthetical to the ethical? And if there is, does it not ultimately defy any attempt at rational explanation in terms of either its genesis and/or possibility or its rationality? Admittedly, I do not have a foolproof answer to these questions. Instead, I rest content with a modest and rather tentative suggestion, which, in the spirit of R. Swinburne, ${ }^{78}$ takes refuge in a C-inductive argument (or argument to the best explanation), which runs as follows: (1) if and as long as we (a) want to hold fast to a belief in the facticity and/or possibility of (cognitive, ethical, religious) framework transitions; if (b) any attempt at explaining the conceptual and/or genetical conditions of these yields a paradox of the type previously spelled out; finally; (c) if any competing hypotheses aimed at accounting for and defending the beliefs in question arrive at either accidental (as in the case of Fisch's externalist intersubjectivity approach) or necessary (as in the case of my own internalist subjectivity approach) conditions for their possible truth and/or rationality at best, then (d) the conclusion seems reasonable that, for the time being, we are well advised to take seriously a perhaps disquieting idea: Framework shifts belong to the class of events or "emergent phenomena" - phenomena, in other words, the instantiation of which entails an irreducible element of contingency, unspecifiability and incomprehensibility with regard to their conceptual conditions and causal antecedents. ${ }^{79}$ (2) This genetical suggestion is to be supplemented and supported by the epistemical observation that framework transitions can be neither rational nor irrational, since these categories pertain to beliefs or volitions within a given framework only; instead, genuine framework transitions should be categorized as trans- or prerational.

4. In conclusion, I would add two brief remarks intended to round off and, I hope, also strengthen my previous argument, namely, by locating it in the context of two more or less recent debates.

4.1. The first has been mentioned already, if only in passing: A. MacIntyre's critique of Either/Or II. Here it should come as no surprise that I find the contention, according to which Judge William describes his friend A as a "person who has not yet embraced either the ethical or the aesthetic," ${ }^{\circ 0}$ deeply flawed, since, as we saw earlier, for both Kierkegaard and his entire circle of pseudonyms such a neither/nor is conceptually, structurally ${ }^{81}$ and psychologically impossible. This notwithstanding, MacIntyre's subsequent claim (which I partly quoted above) is much more to the point; as such its value can and should be appreciated separately from its mistaken counterpart: The "principles which depict the ethical way of life are to be adopted for no reason, but for a choice that lies beyond reason, just because it is the choice of what is to count for us as a reason." ${ }^{2}$ I consider this a very apt genetical and phenomenological description, which as

78 Cf. Swinburne, Existenz Gottes, $15 f$.

79 As is well-known, Kierkegaard's Philosophical Fragments emphasize and further elaborate upon the notion and the eventlike character of framework shifts - here, in particular, with regard to the paradoxical transition from sin to faith qua revelation (cf. Philosophical Fragments, esp. chs. I and II).

80 MacIntyre, After Virtue, xxxvi (my emphasis).

81 Cf. my reading of (the opening passage of) Sickness unto Death above.

82 MacIntyre, After Virtue, xxxviii (my emphasis). 
such nicely captures what actually happens in (here, ethical) framework transitions like the one discussed in Either/Or II. A person who makes such a transition chooses in terms of what I previously dubbed "primary choice," and by definition such choices "lie beyond reason," simply because they genetically/ causally (de re/third person perspective) and phenomenologically (de dicto/first person perspective) determine "what is to count as a reason." Meant here is a choice pertaining to the very conditions and "first principles" of choosing and therefore "no more ultimate reasons can be adduced to support them." 83 Unfortunately MacIntyre seems to consider this a serious, in fact a devastating objection, in that a purportedly "deep internal inconsistency" ${ }^{44}$ or plain "contradiction" ${ }^{85}$ looms large in B's advice to his friend: If and whenever someone chooses "for no reason," his choice must ipso facto be irrational - or so at least MacIntyre seems to think. However, his conclusion is rash, since it is framework shifts that are at issue here, and if my previous argument is roughly correct, such shifts can neither phenomenologically nor epistemically be couched and accounted for in terms of either rationality or irrationality, as both categories exclusively pertain to means-ends-beliefs and to decisions within a given framework, from which follows that those transitions are to be labelled trans- or prerational and MacIntyre's expression "beyond reason" allows and calls for being read apologetically rather than critically.

4.2. My second and final remark pertains to E. Paul's recent and hotly debated theory of the so-called "transformative experiences." 86 In light of the foregoing analysis, I believe to be in principal agreement with the author; nevertheless, I find his approach to be in need of expansion and in fact radicalization. Paul observes that, as opposed to many trivial and transitory experiences, there are also those which are both epistemically and personally transformative. They are epistemically transformative (ETE), if and whenever it is impossible for the subject of experience to know what it will be and feel like to have them before actually having and thus experiencing them "for the first time." ${ }^{87}$ Moreover, the very same experience may also be personally transformative (PTE), namely, if and to the extent that it is "a life-changing experience." ${ }^{88}$ Hence, every PTE is a case of ETE but not vice versa. ${ }^{89}$ Now Paul's major (epistemical) point is that in those situations in which one (a) feels the need to make a choice (between, say, option A and non-A, or between $A$ and B), and in which (b) actualizing at least one of the available options would yield a PTE and/or ETE, the choice in question (though perfectly possible in itself) is not and cannot be rational, at least not by "conforming to the models of an idealized decision theory." 90 If, for instance, "you choose to become a parent, and your choice is based on projections about what you think it would be like for you to have a child, your choice is not rational." 91 Generalizing Paul's point, we might say, then, that radically transforming decisions (e.g., choosing to become a parent, deciding for a certain career path, choosing to live ethically in Judge William's sense, etc.) are possible but not possibly rational: at least not (a) if and as long as they are supposed to be based, among other things, on the respective subject's projections about what it would be like to have made the choice and (b) if rationality is defined in terms of an idealized decision theory. ${ }^{92}$

I principally agree with Paul's diagnosis, yet in light of the foregoing analysis my main objection should not come as a surprise: it does not go far enough, neither genetically nor epistemically. The main reason is that, in those situations in which what is at stake is a (secondary) choice leading to a PTE and/or ETE, the (primary or meta-)choice that this is the case is in fact part and parcel of what is at stake. In other words, we do not only have to choose between A and non-A (or A and B) but also between making this choice or

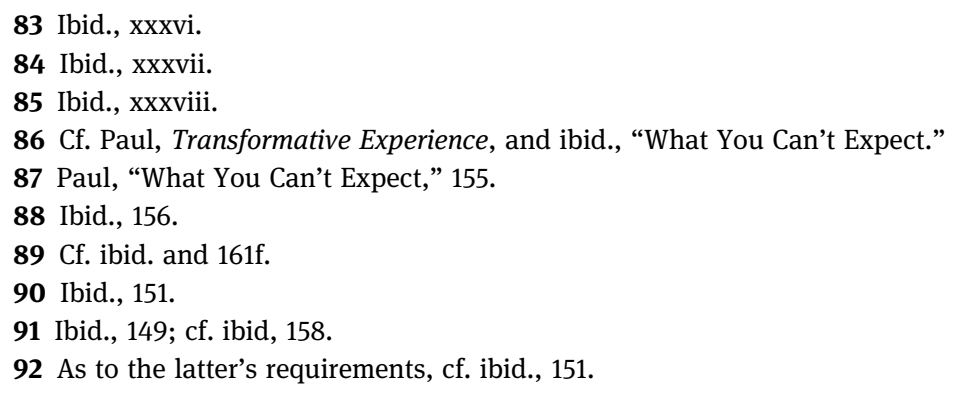


refraining from it - just as in Either/Or II, where the first and most fundamental object of choice turned out to be the momentousness of choosing itself ("here's an either/or, forcing me to make a decision: hic Rhodos, hic salta!"). More precisely, it turned out that we have to make a primary choice or decision that we have to make a secondary choice, and this for the very reason that the latter is to be considered, at least from our own perspective, life changing, hence momentous (=genetical aspect). However, this latter or primary choice is not and cannot be either rational or irrational but neither/nor: it is to be considered, rather, transor prerational, in the sense explained above (=epistemical aspect).

\section{A very brief conclusion}

Let me conclude and round off the previous account with two personal remarks. First, I am happy to admit that, despite my largely critical comments in the preceding sections of my paper, Menachem Fisch's work as a whole has not only been an object of personal admiration and respect, but also been a constant challenge and inspiration for my own thinking throughout the years, since we first met in 2011.

Second - and speaking of challenges - there is, at least in my understanding, no need to feel substantially disquieted by the previous comments (even if they were true): not primarily, and much less only, because being and feeling challenged is precisely what Fisch encourages us to be, to feel and to welcome; but rather, because, if I am not mistaken, my objections exclusively pertain to his beliefs about frameworks (plus the transition between them) - and not to his own framework beliefs, which, as a matter of fact, I believe to share with him in large Davidsonian quantities, and to which I am probably as deeply committed as he is.

Acknowledgments: This article has been published within the framework of the Hessian Ministry for Science and Art funded LOEWE research hub "Religious Positioning: Modalities and Constellations in Jewish, Christian and Muslim Contexts" at the Goethe University Frankfurt and the Justus-LiebigUniversity Giessen.

\section{References}

Amir, Lydia. "Stages." In Kierkegaard's Concepts. Tome VI: Salvation to Writing, edited by Steven M. Emmanuel et al., 89-96. Farnham: Ashgate Publishing, 2015.

Audi, Robert. Rationality and Religious Commitment. Oxford: Clarendon Press, 2011.

Buber, Martin. Tschuang-Tse: Reden und Gleichnisse. Trans. by M. Buber. Zurich: Manesse, 1990 [1951].

Davenport, John J., and Rudd, Anthony (eds.). Kierkegaard after MacIntyre. Essays on Freedom, Narrative and Virtue. Chicago and La Salle, IL: Open Court, 2001.

Davenport, John J. Narrative Identity, Autonomy, and Mortality. From Frankfurt and MacIntyre to Kierkegaard. New York and London: Routledge, 2012.

Davidson, Donald. Inquiries Into Truth and Interpretation. Oxford: Clarendon Press, 1984.

Dennett, Daniel. Elbow Room. The Varieties of Free Will Worth Wanting. Cambridge, MA: MIT Press, 1984.

Evans, C. Stephen. Kierkegaard's Ethic of Love. Divine Commands \& Moral Obligations. Oxford: Oxford University Press, 2006. Ferreira, Jamie M. Transforming Vision. Imagination and Will in Kierkegaardian Faith. Oxford: Oxford University Press, 1991. Fisch, Menachem. "A Modest Proposal: Towards a Religious Politics of Epistemic Humility.” Journal of Human Rights 2 (2003), 49-64.

Fisch, Menachem and Benbaji, Yitzhak. The View from Within: Normativity and the Limits of Self-Criticism. Notre Dame, IN: University of Notre Dame Press, 2011.

Fisch, Menachem. “Deciding by Argument versus Proving by Miracle: The Myth-History of Talmudic Judaism's Coming of Age.” Toronto Journal of Theology, Supplement 1 (2017), 103-26.

Fisch, Menachem. "Lost for Words. Rethinking Normative Ambivalence." Unpubl. Mscr., 2017.

Fisch, Menachem. “Ambivalence as a Jewish Value.” 2017. http://www.tabletmag.com/jewish-arts-and-culture/245849/ ambivalence-as-a-jewish-value/?print=1; last visited 04/05/2020. 
Fisch, Menachem. “The Normative Challenge of Talmudic Judaism's Rational Theology.” Unpubl. Mscr., 2017.

Fisch, Menachem. “The Talmudist Enlightenment. Talmudic Judaism's Confrontational Rational Theology.” European Journal for the Philosophy of Religion 12 (2020), 37-63.

Gadamer, Hans-Georg. Wahrheit und Methode. Tübingen: J.C.B. Mohr, 1975.

Godlove, Jr., Terry F. Religion, Interpretation, and Diversity of Belief. The Framework Model from Kant to Durkheim to Davidson. Macon, GA: Mercer University Press, 1997.

Hannay, Alastair. Kierkegaard, 3rd edn. London and New York: Routledge, 1993.

James, William. “Der Wille zum Glauben.” In Pragmatismus. Ausgewählte Texte, edited by E. Martens, 128-60. 2nd edn. Stuttgart: Reclam, 1992.

Jules-Rosette, B. African Apostles: Ritual and Conversion in the Church of John Maranke. Ithaca, NY: Cornell University Press, 1975.

Kierkegaard, Søren. Journals and Papers, vol. 4. Edited and trans. by Howard V. Hong and Edna H. Hong. Bloomington, IN/ London: Indiana University Press, 1975.

Kierkegaard, Søren. The Concept of Anxiety. Edited and trans. by Howard V. Hong and Edna H. Hong. Princeton, N): Princeton University Press, 1980.

Kierkegaard, Søren. The Sickness unto Death. A Christian Psychological Exposition for Upbuilding and Awakening. Edited and trans. by Howard V. Hong and Edna H. Hong. Princeton, NJ: Princeton University Press, 1983.

Kierkegaard, Søren. Either/Or, vol. I and II. Edited and trans. by Howard V. Hong and Edna H. Hong. Princeton, NJ: Princeton University Press, 1987.

Kierkegaard, Søren. Philosophical Fragments. Johannes Climacus. Edited and trans. by Howard V. Hong and Edna H. Hong. 2nd edn. Princeton, NJ: Princeton University Press, 1987.

Kierkegaard, Søren. Concluding Unscientific Postscript to Philosophical Fragments, vol. 1. Edited and trans. by Howard V. Hong and Edna H. Hong. Princeton, NJ: Princeton University Press, 1992.

Kierkegaard, Søren. Upbuilding Discourses in Various Spirits. Edited and trans. by Howard V. Hong and Edna H. Hong. Princeton, NJ: Princeton University Press, 1993.

Lauth, Reinhard. Die absolute Ungeschichtlichkeit der Wahrheit. Stuttgart: Kohlhammer, 1966.

Lippitt, John and Stokes, Patrick (eds.). Narrative, Identity and the Kierkegaardian Self. Edinburgh: Edinburgh University Press, 2015.

Marino, Gordon. “The Place of Reason in Kierkegaard's Ethics.” In Davenport, Kierkegaard after MacIntyre, 113-27, 2001.

Paul, L. A. Transformative Experience. Oxford: Oxford University Press, 2014.

Paul, L. A. "What You Can’t Expect When You Are Expecting." Res Philosophica 92 (2015), 149-70.

Piety, Marilyn G. “Kierkegaard on Rationality.” In Davenport, Kierkegaard after Maclntyre, 59-74, 2001.

Rambo, Dalton. Understanding Religious Conversion. New Haven, CT: Yale University Press, 1993.

Schmidt, Jochen. “'Das moralische Gesetz ist heilig (unverletzlich)'. Versuch zu den Grenzen vernünftiger Rechenschaft über moralische Geltungsansprüche im Anschluss an Kant.” In Interesse am Anderen. Interdisziplinäre Beiträge zum Verhältnis von Religion und Rationalität, edited by G. Schreiber, 643-64. Berlin/Boston: De Gruyter, 2019.

Schulz, Heiko. Eschatologische Identität. Eine Untersuchung über das Verhältnis von Vorsehung, Schicksal und Zufall bei Sören Kierkegaard. Berlin/New York: De Gruyter, 1994.

Schulz, Heiko. "Positionalität und Perspektivität. Theologiepropädeutische Überlegungen." In Wahrheit und Positionalität. Theologische Perspektiven, edited by Melanie Köhlmoos and Markus Wriedt, 125-52. Berlin: Evangelische Verlagsanstalt, 2012.

Schulz, Heiko. "Conversion, Truth and Rationality." In The Idea of Religious Conversion, edited by Ingolf U. Dalferth and Michael Rodgers, 179-213. Tübingen: J.C.B. Mohr, 2013.

Schulz, Heiko. "Theology and Rationality: Some Conceptual and Epistemic Remarks.” Toronto Journal of Theology 29 (2013), 281-97.

Schulz, Heiko. “Einleitung.” In Religion und Irrationalität. Historisch-systematische Perspektiven, edited by Jochen Schmidt and Heiko Schulz, vii-xxxiv. Tübingen: Mohr Siebeck, 2013.

Sousa, Ronald de. The Rationality of Emotion. Cambridge, Mass.: MIT Press, 2001.

Swinburne, Richard. Die Existenz Gottes. Trans. by R. Ginters. Stuttgart: Reclam, 1987.

Theunissen, Michael. “Kierkegaard's Negativistic Method." In Kierkegaard's Truth. The Disclosure of the Self, edited by J. H. Smith, 381-423. New Haven, Conn.: Yale University Press, 1981.

Žižek, Slavoj. Event. A Philosophical Journey through a Concept. London: Melville House, 2014. 